\title{
Cantar de ciego: una hipótesis del oficio trovadoresco en la provincia de San Esteban de Gormaz (Soria) durante el siglo XII
} Sing of the blind: a hypothesis of the troubadour office in the province of San Esteban de Gormaz (Soria) during the twelfth century

\author{
Abel Mostaza Prieto \\ Graduado en Historia y Ciencias de la Música, Universidad de Valladolid, España (abel.mostaza.prieto@hotmail.com)
}

RESUMEN: La música instrumental de los tiempos pretéritos es en gran parte un misterio. Aquella cuyo legado nos llega desde el siglo XII hasta hoy sólo se conservaba en manuscritos mudos que requieren de una hipotética reinterpretación acerca de cómo podría sonar aquel mundo. Sin embargo, gracias al arte arquitectónico de algunos templos, así como los poquísimos ejemplares conservados de ese periodo románico, la arqueomusicología ha podido recrear su fisionomía y probable sonoridad.

De forma testimonial, esos mismos instrumentos presentan orígenes diversos, a la par que nos ofrecen un ideal histórico y religioso de una sociedad donde el arte de la guerra convivía con el Arte (en mayúsculas). La transmisión e intercambio de cultura se ha estampado precisamente en las representaciones escultóricas de esos templos, probablemente como una crítica cristiana de actividades inmorales; la provincia de San Esteban de Gormaz nos da una muestra de todo ello.

PALABRAS CLAVE: Música, Arte, Historia, Románico, Soria

\begin{abstract}
The medieval music is a mystery. The one whose legacy comes from the 12th century until today is only preserved in muted manuscripts that require a hypothetical reinterpret of how world might sound. However, thanks to the architectural art of some temples as well as the few specimens preserved from this Romanesque period, the Music Archaeology has been able to recreate its physiognomy and probable sonority.
\end{abstract}

In a testimonial way, these same instruments present diverse origins as they offer us a historical and religious ideal of a society where the art of war coexisted with Art (in capital letters). The transmission and exchange of culture has been stamped precisely in the sculptural representations of these temples, probably as a Christian critique of immoral activities, and the province of San Esteban de Gormaz gives us a sample of all this. 
KEYWORDS: Music, Art, History, Romanesque Art, Soria

\section{Introducción}

Poco es el conocimiento que tenemos acerca de los estamentos sociales más humildes y de la vida urbana del siglo XII si lo comparamos con la denominada «contemporaneidad»; podemos establecer una serie de conjeturas a través del legado artístico-arqueológico y de los textos conservados por colegiatas, monasterios, abadías y las primeras universidades. Más allá de esto sólo la imaginación del «yo» como devenir histórico permite idear el modus vivendi del pueblo llano, de ese tercer estado anclado en el sistema feudal cuya estratificación no decayó de una forma más o menos definitiva hasta bien entrado el siglo XIX ${ }^{1}$. Un esbozo de su dedicación y sus oficios nos han llegado a través de cantares o romances, de la «literatura de cordel», de esculturas o pinturas... en definitiva, desde el paraguas del «mundo del arte».

La provincia de Soria y en concreto las poblaciones circundantes de San Esteban de Gormaz son un ejemplo artístico de este siglo XII: esculturas, arquitectura religiosa, pinturas, tradiciones e incluso cantigas nos hablan de esta frontera entre los reinos cristianos y los primeros reinos de taifas; y es sin duda alguna en ellos donde más enfrentamientos y convivencias se debieron dar entre estas culturas.

Pero definamos ahora el contexto musical de la Baja Edad Media (siglos XI-XV). A grandes rasgos podemos decir que la cultura musical se resume en dos vías: la música religiosa (de la que conservamos mayor cantidad de manuscritos) y la música popular o profana (de la que conservamos algunas jarchas, cantigas, romances). Los primeros reprobaban a los segundos por «dedicarse a espectáculos indecorosos condenables por su frivolidad y, también, por su frecuente vida licenciosa»

1 Sabemos bien que esto es discutible como toda «permanencia histórica». No son pocos los historiadores que se han levantado contra el estilismo periódico según el cual es estilo se practica exclusivamente entre dos fechas dadas como si todo tuviese que tener un principio y un final; ejemplos de ello puede ser la intención de algunos musicólogos en clasificar el barroco musical desde la invención de la ópera en torno al año mil seiscientos y cerrarlo con la muerte de J. Sebastián Bach en 1750 (las peculiaridades que definían el barroco musical continuaron, entre otros, con algunos de los hijos de Bach). En definitiva, algunos historiadores podrían sentenciar nuestra frase aludiendo a que el sistema feudal termina con el Renacimiento o con el alzamiento de la burguesía medieval, pero no podrán negarnos que los principios estructurales que regían ese sistema feudal continuaron hasta el siglo XIX y aún hoy queda una pequeña lastra de aquello en nuestra propia sociedad. Si aún cabe debate acerca de ello, basta con analizar la historia desde la corriente del materialismo histórico (el cual ya se percató del clasismo en el siglo XIX). 
(Yzquierdo, 1997, p. 68) ${ }^{2}$; los segundos tachaban de moralistas e hipócritas a los primeros mediante la sátira o la crítica social (Hoppin, 2000, 259). Ante este panorama cabe pensar que la hibridación era difícil sino imposible, pero los intercambios musicales entre Clero y Pueblo Llano no eran tan infrecuentes: algunas composiciones (como los conducti ${ }^{3}$ ) del clero tomaban melodías de juglares y viceversa. Dado que nuestro objetivo es buscar una relación de los modillones y capiteles con la música juglaresca, nos centraremos sólo en esta última.

Ya el profesor Ramón Yzquierdo se percató de una constante entre el Camino de Santiago ${ }^{4}$ y la imaginería de juglares a lo largo de éste. Pero, ¿qué podemos entender por juglar y por trovador? Según Menéndez Pidal la palabra juglar es un término «de significación muy ancha, que ha sido sentido de muy varios modos, según las circunstancias y las épocas (...) todos los que se ganaban la vida actuando ante un público» (Menéndez Pidal Citado en Yzquierdo, 1997, p. 68). El juglar es ante todo un actor, un hombre dedicado a entretener a su público valiéndose de historias, canciones, danzas y cabriolas e incluso como sanador -muchos de ellos ejercían de «médicos» o curanderos tras sus espectáculos- (Hoppin, 2000, p. 280). Por su parte, trovadores (y troveros), salvando las distancias y admitiendo el reduccionismo por nuestra parte, se ajustarían más a nuestra idea de compositor. Mientras los juglares serían profesionales de oficio (personas dedicadas a ganarse la vida con ese trabajo), los trovadores y troveros serían profesionales de estudio (personas dedicadas a componer ${ }^{5}$ ).

Ahora centrémonos en los músicos profanos (aunque los términos a veces son difusos): juglares, trovadores y troveros. Aunque estos vocablos nos recuerdan al origen francés, la Península Ibérica será crucial para ellos por diversas circunstancias. Si tuviéramos que definir a grandes rasgos las características principales de estos compositores-músicos para nuestra hipótesis, diríamos que los troveros se mantuvieron más o menos al norte del Loira mientras los trovadores se situarían bajo este río (llegando incluso a atravesar los Pirineos o Los Alpes Italianos). Los trovadores se dedicaban

\footnotetext{
${ }^{2}$ Sin embargo, nosotros no debemos olvidar que el alto clero gozaba casi de la misma condición y estilo de vida que los nobles y reyes, no es difícil imaginar a Obispos con sus propios juglares (Yzquierdo, 1997, p. 68).

${ }^{3}$ Como puede ser el caso de Veris ad imperia (Por el poder de la primavera) que toma su tenor de la canción popular l'entrada del tens clar (Al principio del buen tiempo) (Hoppin, 2000, p. 261). *Reconociendo que el término Conductus pertenece a la cuarta declinación (pl. Conductus), empleamos aquí el plural de la segunda declinación (conducti) porque es el empleado habitualmente en el acervo musical de la música antigua.

${ }^{4}$ Como veremos, San Esteban de Gormaz se encuentra en la denominada Vía de la Lana, camino no tan antiguo ni popular como el francés, pero sí con varios rasgos definitorios del románico francés (como por ejemplo el uso del taqueado jaqué en frisos, arquivoltas y cenefas volumétricas murales).

5 E aquí uno de los pecados reduccionistas cometidos: las diferencias entre trovadores, troveros y juglares no están del todo clarificadas. Como no es nuestro cometido para este artículo comentarlas, hemos optado por clasificarlos en dos grandes grupos según fuesen o no compositores (aunque admitimos que tanto juglares como trovadores podían ser compositores e intérpretes).
} 
principalmente a la composición de canción vital o mudanza (canciones populares, escarnios, sirventes, enueg y planh, danzas, etc) frente al idílico amor cortés de los troveros (caballería, gestas, etc.). Esta introducción permite imaginarnos a aquellos trovadores que, perseguidos por la cruzada albigense, encontraron servicio de sus canciones «libertinas» en las cortes de las penínsulas italiana e hispana. Recapitulemos: unos músicos amorales (juglares) y unos compositores-intérpretes (trovadores) mantienen sus formas y tipología de poemas y canciones más allá de los Pirineos mientras sus homólogos aristócratas (troveros) difunden sus composiciones hacia el norte europeo.

Pero, ¿por qué elegir San Esteban de Gormaz como testimonio práctico del oficio de músico? La respuesta nos la da, una vez más, la dura y fría piedra ${ }^{6}$, algunas peculiaridades en la imaginería arquitectónica de las Iglesias de La Virgen del Rivero y de San Miguel en San Esteban de Gormaz; y de la Ermita de Santa María en las cercanías de la histórica y multicultural Tiermes. Siconocemos los patrones generales de ubicación de los músicos de este periodo de florecimiento del románico, veremos como normativo situar a los músicos en la arquivolta superior de los pórticos, pues la música aparece ilustrada organológicamente como un coro celestial de ancianos tañendo fídulas, albogues arpas, vihuelas, panderos, atabales o el genuino organistrum central. Pero esto no ocurre en ninguno de los templos propuestos.

Empezamos nuestra ruta en San Esteban de Gormaz, dotada en la actualidad de dos templos románicos conservados en bastante buen estado. Si ascendemos hacia el castillo, las primeras representaciones musicales las encontraremos en Santa María del Rivero. Accediendo a la galería, un capitel situado a la izquierda de la portada a la altura de los ojos del espectador nos da la bienvenida con una fídula [1]. A la espalda, a la altura del hombro derecho del espectador, un capitel situado en la primera columna que da acceso a la galería porticada por su fachada sur muestra un intérprete de cornamusa [2]. Esta organología y su ubicación es extraña en el románico, cierto, pero tampoco es casual que el hombre que toca la cornamusa se encuentre en la galería porticada mientras su homónimo de cuerda está en la portada (Gaya, 1946, p. 54). La cornamusa era un instrumento histriónico, asociado a las clases populares y que rara vez tenía sitio en la interpretación eclesiástica (procesiones, por ejemplo), por eso no es descabellado encontrarlo como antecedente al templo, ¡más si tenemos en

\footnotetext{
${ }^{6}$ En primer lugar, acudimos a PARES para buscar documentación del siglo XII que referenciase a músicos, tañedores o juglares en esta zona; lamentablemente los resultados no dieron frutos y, aunque algunos de los documentos son muy interesantes, ninguno aludía a músicos del siglo XII en la zona. Sin nombres no podíamos acudir a archivos como el Archivo Diocesano.
} 
cuenta esa especie de capucha que lleva en la cabeza; parece que nos dice «lo profano ha de dejarse fuera del templo».

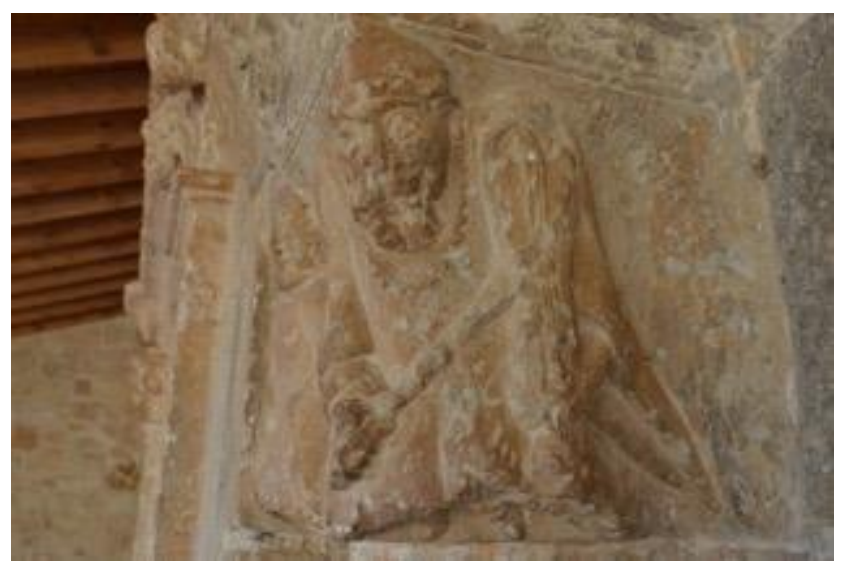

1. Ministril tañendo una fídula en Santa María del Rivero (San Esteban de Gormaz). Fotografía de Abel Mostaza Prieto.

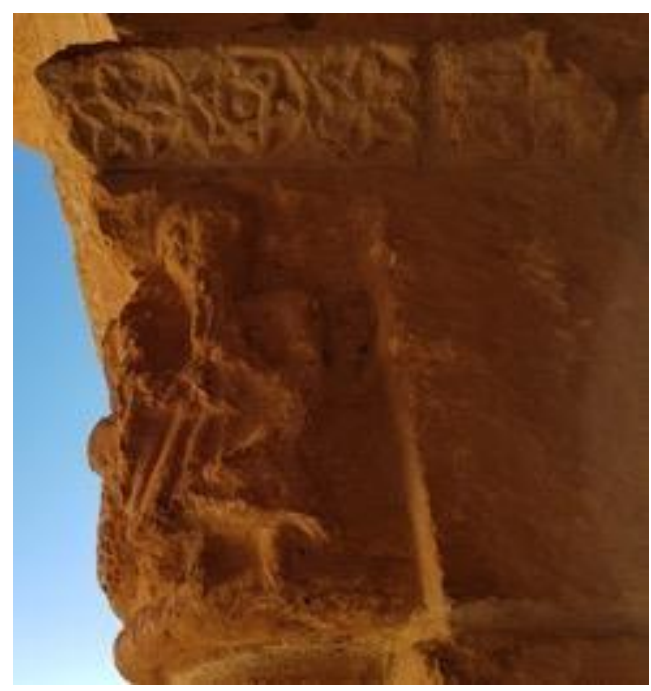

2. Ministril soplando una cornamusa en Santa María del Rivero (San Esteban de Gormaz). Fotografía de Abel Mostaza Prieto

Si seguimos nuestro ascenso al castillo, a pocos metros al pie de éste, nos toparemos con la Iglesia de San Miguel. Situándose en la primera columna derecha de la galería porticada sur, el espectador encontrará un capitel historiado con varios personajes [3] que parecen estar interpretando algo en conjunto (¿ministriles?). Aunque en comparación con los otros ejemplos se encuentra en peor estado, se pueden detectar claramente un vihuelagambista y a un fidulista con ropajes anchos, típicos de musulmanes y moriscos (Gaya, 1946, p. 47). Al igual que el caso anterior, estos músicos están desubicados respecto a su posición costumbrista en el arte románico bajo medieval al no hallarse en el 
pórtico. Los motivos por los que están en un capitel se amplían considerablemente: una escena bíblica ${ }^{7}$, una actividad propia o un suceso histórico de la zona, quizá.

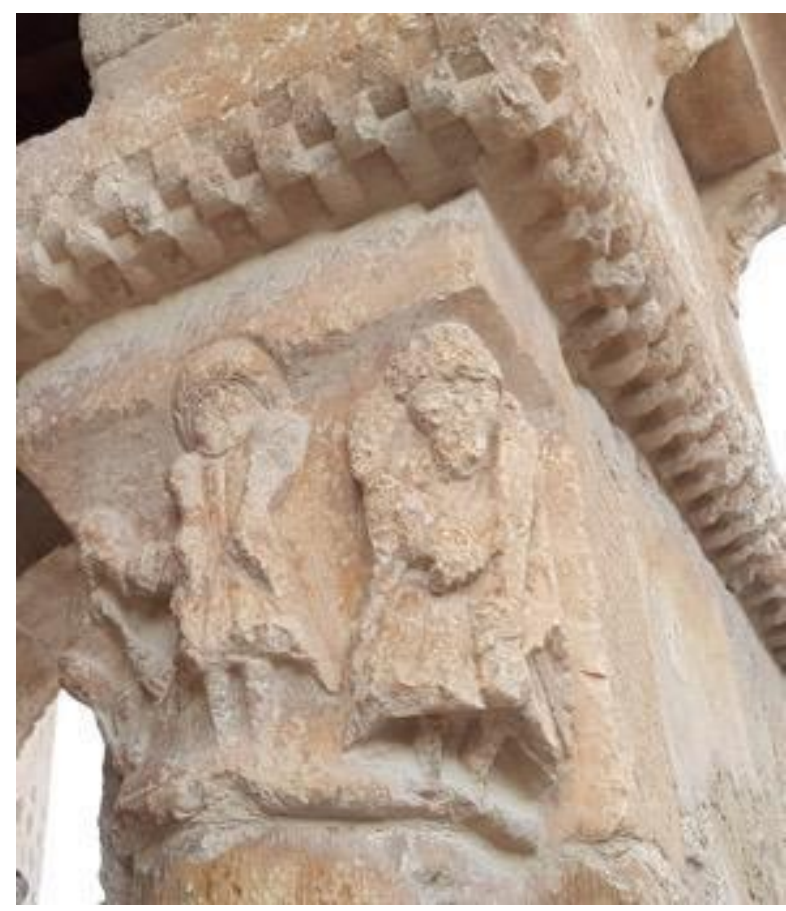

3. Ministriles en un capitel de la iglesia de San Miguel (San Esteban de Gormaz).

Fotografía de Abel Mostaza Prieto

El tercer caso lo encontramos a escasos kilómetros de San Esteban de Gormaz: la Ermita de Sta. María de Tiermes. Allí un magnifico un templo románico es rodeado por un valle plagado de ruinas testigo del paso romano y celtíbero. En el exterior del templo podemos destacar sus canecillos historiados conservados en bastante buen estado, pero para nuestro cometido nos fijaremos en uno situado en la cornisa del ábside que mira al sur, donde figura un músico que tañe un fídula con extraños ropajes (hábito y turbante), un poblado bigote y lo que parecen unos zuecos o unas pezuñas de cerdo [4] (Gaya, 1946, p. 77). Del mismo modo que los músicos suelen encontrarse en la arquivolta del pórtico, tampoco es habitual que los canecillos muestren esta iconografía más allá de los típicos motivos moralistas, marginados, grutescos o motivos vegetales, seres mitológicos y oficios. De estas

7 El músico favorito del arte románico es sin duda el rey David interpretando con su cítara. Pero éste no es tampoco el caso. 
opciones podemos reducir a dos el porqué podría situarse aquí este simpático personaje: o bien es un motivo moralista-marginado (quizá se trate de un morisco) o bien se trata de un oficio de la zona.

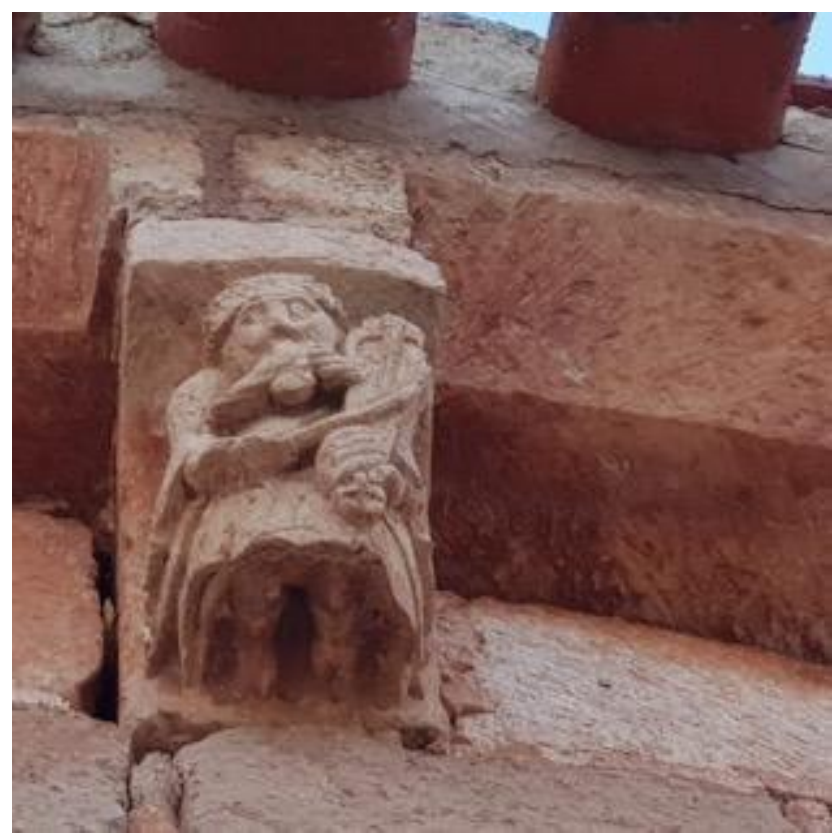

4. Ministril tañendo una fídula en Santa María de Tiermes (Tiermes).

Fotografía de Abel Mostaza Prieto

\section{Conclusiones}

Llegados a este punto nos debemos preguntar cómo es posible que estas representaciones se sitúen en lugares tan privilegiados: bien si son moriscos, bien si son campesinos, bien si son motivos moralistas eclesiásticos, todos estos gozan de una ubicación notable para lo que canecillos y capiteles del arte románico de esta época se suele representar.

En primer lugar, diremos que la Villa de San Esteban de Gormaz tiene gran importancia histórica: en pleno Camino de la Lana, Alfonso X «el Sabio» se alojó en dos ocasiones en la Villa y «dispuso» ${ }^{8}$, al igual que el autor del «Cantar del Mío Cid», algunas de sus composiciones allí; fue un enclave de resistencia fronteriza cristiana con los musulmanes ${ }^{9}$; en ella se convocaron las Cortes de

8 Ponemos el término entrecomillado ya que hay un consenso entre literatos y musicólogos al respecto de la autoría de estas composiciones. El Camino de la Lana a Santiago coincide en su paso con San Esteban de Gormaz también como Camino de Levante.

9 De hecho, cuando acudimos a buscar información a los archivos, nos recomendaron buscar el poblado con el término "Castromoro". Parece ser que este fue el nombre de la villa durante un tiempo. 
Castilla... (Gaya, 1946, pp. 39-40). Podríamos relatar en detalle muchas más, pero para nuestra hipótesis basta con observar éstas.

En segundo lugar, podemos imaginarnos la importancia que tuvo la música ${ }^{10}$ en todo este territorio. De ello dan muestra sus capiteles y modillones; un simple juego mental -aunque asumimos puede ser falaz- nos permite imaginar que aquello que es representado con tanto detalle debe haberse conocido de cerca. Una fídula puede ser -morfológicamente hablando- más difícil de representar que un león, sin embargo, estas representaciones bestiales suelen ser amorfas, mientras aquellas musicales gozan de gran detalle en las formas. A diferencia de los grandes felinos, debían conocer en detalle el instrumento y la posición en la que los músicos interpretaban, de lo que deducimos como cabal el pensar que probablemente hubiesen visto esos instrumentos en varias ocasiones, pero no leones.

Asumiendo lo dicho hasta aquí, el axioma se deduce inmediatamente. Sin duda alguna San Esteban de Gormaz debió ser un núcleo musical profano importante junto con algunas de sus provincias. Esta música no entendía de religiones, sino de realidades, de lo que era la práctica existente y popular. Dado los ropajes con los que se representa a alguno de los ministriles, es muy probable que cristianos, moriscos y musulmanes viviesen armoniosamente como intérpretes. Muestra de ellos es la ubicación de las representaciones citadas en los templos: el oficio de músico profesional ${ }^{11}$ (o ministril) debía de ser un oficio propio de la zona (los marginalia). La Iglesia no debía dedicar buenos sermones en público a esa música licenciosa y terrenal interpretada en conjunto con paganos ${ }^{12}$, pero sí que conoció de ella en un ámbito privado e íntimo. Ésta es pues nuestra hipótesis: la música era un vínculo cultural que se producía no sólo en la villa (y alrededores), sino en toda Soria en general ${ }^{13}$; la provincia era un núcleo importante donde probablemente ministriles de diferentes creencias religiosas, pero oriundos de una misma localidad, participaban de los grandes eventos convocados por y para los nobles; sí, pero sobre todo donde la población de "a pie” conocería y participaría de una música popular que no discriminaba por fe. Es por esto que la doctrina cristiana medieval advirtió de estas prácticas

10 En el devenir histórico, la zona limítrofe entre Burgos y Soria ha visto pasar a trovadores, troveros y juglares de la talla de Men Rodríguez Tenorio, Johan Vasquiz de Talaveira, Gómez García, Alfonso X, Pedro García Burgalés, Lope Díaz de Haro y Rodrigo Díaz de los Cameros.

11 Entendiendo esto con los dos sentidos actuales del término: «aquel que se dedica por oficio a la música» (profesión) pero también «aquel que tiene conocimientos avanzados de la música» (profesionalidad).

12 Técnicas como el contrafactum yla misa parodia son una buena muestra de la hibridación que llegó a producirse entre las músicas populares-profanas y la música religiosa en general.

${ }^{13}$ Ejemplos a mayores de los propuestos son la mágica Ermita de San Baudelio de Berlanga (Casillas de Berlanga) o la Iglesia y Claustro de San Juan de Duero (Soria) -la cual también está marcada por historias de templarios-. 
en sus sculpturae officiorum, situando éstas en capiteles y canecillos para juzgarlos como moralmente ambiguas y reprochables en el oficio público.

\section{Referencias bibliográficas}

Arnaiz Alonso, Benito; y Rodrigo Mateos, Ma . Carmen (1993). El Románico en torno al Camino de Santiago en Castilla y León. Biblioteca El Norte de Castilla.

FATÁS, Guillermo; y BORRÁS, Gonzalo M (2016). Diccionario de términos de Arte y elementos de Arqueología, Heráldica y Numismática. Alianza Editorial: Bilbao.

Gaya Nuño, Juan Antonio (1946). El Románico en la Provincia de Soria. Consejo Superior de Investigaciones Científicas: Madrid.

Gómez GómeZ, Agustín (1946). El Protagonismo de los otros. La imagen de los marginados en el Arte Románico. Centro de Estudios de Historia de Arte Medieval: Madrid.

Hoppin, Richard (2000). La música medieval. Traducido por Pilar Ramos López. Akal Música: Colmenar Viejo.

PORRAS Robles, Faustino (2007). Los instrumentos musicales en el Románico Jacobeo: estudio organológico, evolutivo y artístico-simbólico. Biblioteca Virtual de Miguel de Cervantes: Alicante.

YZQUIERDo PERRÍN, Ramón (1997), "Escenas de juglaría en el románico de Galicia". O Camiño Inglés $e$ as rutas atlánticas de peregrinación a Compostela. A Coruña, Universidade. Servizo de publicacións, 1997, pp. 67-102. 